\title{
Popularitas Merek di Sosial Media: Analisis Pengaruh Waktu, Konten, dan Interaksi Merek
}

\author{
Tri Hanifawati ${ }^{1 *}$, Utan Sahiro Ritonga ${ }^{2}$, Euis Evi Puspitasari ${ }^{3}$ \\ 1,2,3 Universitas Muhammadiyah Bandung \\ 1trihanifawati@gmail.com, ${ }^{2}$ utan_r@ymail.com, ${ }^{3}$ tukdewipuspita@gmail.com \\ *Penulis korespondensi
}

\begin{abstract}
Social media is an effective media to increase brand popularity. Previous studies found that the brand has significant effects on the consumers purchasing decision. Indicator of brand popularity on social media includes the number of followers, likes, shares, comments, and views of the video. The objective of this study is to analyze the effects of post time, post content, and brand interaction on brand post popularity of Facebook fan page. Data collected through observation of six (6) international top brands on the Facebook fan page. Data were analyzed using logit regression method. The results show that post time, post content, and brand interaction have significant effects on brand popularity. The managerial implication, it is crucial to highlight that Facebook is a useful platform on brand popularity building. Our discussion section shows some suggested in managing the brand based on our results.
\end{abstract}

Keywords: brand popularity, branding strategy, marketing communication, social media

\begin{abstract}
Abstrak
Sosial media merupakan media yang sangat efektif untuk meningkatkan popularitas merek. Berbagai penelitian telah menemukan bahwa merek berpengaruh signifikan terhadap keputusan pembelian. Adapun indikator popularitas merek di sosial media meliputi jumlah followers, sukai, komentar, bagikan, dan tayangan khusus untuk video. Penelitian ini bertujuan untuk menganalisis pengaruh waktu, konten, dan interaksi merek terhadap popularitas merek di fanpage Facebook. Pengumpulan data dilakukan melalui observasi enam top merek internasional kategori produk makanan-minuman. Data dianalisa dengan metode regresi logit. Hasilnya ditemukan bahwa waktu, konten, dan interaksi merek berpengaruh signifikan terhadap popularitas merek. Implikasi manajerialnya, sangat penting untuk digarisbawahi bahwa Facebook masih menjadi platform yang sangat efektif untuk membangun popularitas merek. Pada bagian diskusi, kami memberikan beberapa rekomendasi startegi untuk mengelola merek berdasarkan temuan study kami.
\end{abstract}

Kata kunci: popularitas merek, strategi branding, komunikasi pemasaran, sosial media 


\section{PENDAHULUAN}

Merek didefinisikan sebagai nama, istilah, tanda, simbol, rancangan, atau kombinasi dari semuanya yang dimaksudkan untuk mengidentifikasi produk dan membedakannya dari pesaing (Combe 2006; Kotler \& Keller 2009). Membangun merek yang kuat adalah pekerjaan yang kompleks sebab merek lebih dari sekedar nama dan lambang (Vukasovič 2013; Abidin dkk. 2014). Merek adalah elemen kunci dalam membangun hubungan perusahaan dengan konsumen (Kotler \& Keller, 2009). Produk yang memiliki merek yang kuat, akan lebih mudah memenangkan persaingan (Rangkuti, 2009). Beberapa merek seperti Indomie, Coca Cola, Starbuck, mampu menjadi ikon produk makanan-minuman dan mempertahankan kekuatan mereka di pasar sampai melewati beberapa generasi.

Salah satu alat branding yang sangat potensial di abad digital ini adalah sosial media. Bagian terpenting dari platform ini adalah kelebihannya dalam membangun electronic word of mouth (e-WOM) berupa pesan berantai yang dilakukan melalui fitur post, berbagi dan komentar. Beberapa manfaat sosial media antara lain dapat mempercepat akses merek (Vukasovič 2013; Kim \& Johnson 2016), meningkatkan komunikasi pemasaran (Sabate dkk. 2014; Wang dkk. 2015), dan memberikan informasi produk untuk meningkatkan profit perusahaan (Verhoef \& Lemon, 2013). Manfaat lain yakni meningkatkan popularitas merek, ide, dan jasa untuk target grup khusus; memberikan informasi target audiens tentang produk yang ditawarkan; mendorong kompetisi pasar yang sehat; menyediakan manfaat sosial; serta membangun interaksi dengan konsumen dan menjaga loyalitas mereka (Jothi, Neelamalar, \& Prasad, 2011). Konsumen dapat belajar, berbagi informasi, berinteraksi, membeli, dan bahkan mengevaluasi suatu merek melalui sosial media (Hudson, dkk. 2015). Industri makanan di Slovania misalnya telah banyak yang sukses membangun merek melalui sosial media (Vukasovič, 2013).

Facebook merupakan jaringan sosial media dengan jumlah user terbesar untuk memperkenalkan merek, mulai dari skala usaha yang paling besar sampai paling kecil di dunia (Gamboa \& Gonçalves 2014; Kemp 2016). Facebook menyediakan fitur posting berbagai konten (teks, gambar, video), komentar, views video, sharing konten, dan fan page sebagai halaman khusus untuk bisnis, institusi, atau komunitas. Dengan berbagai fitur tersebut, merek dapat berkomunikasi langsung dengan konsumen, menampilan informasi terbaru produk, dan menambah konsumen baru (Wang dkk., 2015), konsumen pun menjadi lebih aktif mengumpulkan informasi dan berbagi pendapat tentang merek tersebut (Kim \& Johnson, 2016).

Berbagai penelitian terdahulu telah menemukan bahwa merek berpengaruh signifikan terhadap keputusan pembelian konsumen (Magnini, Karande, Singal, \& Kim, 2013; Saboo, Kumar, \& Ramani, 2016; Kudeshia \& Kumar, 2018). Nama merek bahkan ditemukan berpengaruh lebih besar terhadap persepsi konsumen, pemilihan alternatif, dan perilaku setelah pembelian (Hanifawati, Suryantini, \& Mulyo, 2017). Penelitian lain menyebutkan bahwa popularitas merek berhubungan erat dengan niat pembelian, pembelian aktual, dan penentuan harga (Lin, Swarna, \& Bruning, 2017). Berbagai penemuan tersebut menunjukkan bahwa meningkatkan popularitas merek menjadi penting untuk dijadikan sebagai salah satu fokus bidang pemasaran. 
Popularitas merek merupakan fungsi dari jumlah follower dan waktu (Zadeh \& Sharda, 2014). Sedangkan penelitian lain menemukan bahwa popularitas merek berhubungan signifikan dengan jumlah follower, jumlah karakter pesan teks, gambar, video, dan jam posting (Sabate, dkk., 2014); jenis konten, timing, dan interaktifitas merek dalam bentuk link, hastag, kontes, maupun voting (Schultz, 2017). Tidak ada perbedaan signifikan terhadap efektivitas pesan antara tipe pesan informatif, hiburan, dan promosi, namun ketiga tipe konten pesan ini berpengaruh signifikan dalam membangun hubungan dengan user (Rog, 2014). Pesan berupa video dan gambar lebih disukai daripada pesan teks (Brookes, 2010), dengan kata lain pesan visual lebih efektif untuk meningkatkan popularitas merek di sosial media daripada pesan verbal. Popularitas merek di sosial media dalam hal ini diukur berdasarkan jumlah likes, komentar (Sabate, dkk., 2014; Swani \& Milne, 2017) dan share (Schultz, 2017). Post gambar dan video berpengaruh signifikan untuk meningkatkan jumlah likes, sedangkan gambar dan waktu publikasi berpengaruh terhadap jumlah komentar (Sabate dkk., 2014). Schultz (2017), juga menemukan bahwa gambar berpengaruh signifikan terhadap jumlah like, komentar dan share sedangkan video hanya berpengaruh signfikan terhadap jumlah komentar dan share. Dengan demikian diduga kuat bahwa konten post berupa gambar, video, dan caption berpengaruh signifikan terhadap popularitas brand di sosial media. Adapun konten visual berupa video dan gambar diduga lebih efektif untuk meningkatkan popularitas daripada pesan verbal. Maka kami mengembangkan hipotesis sebagai berikut:

$\mathrm{H}_{1}=$ gambar berpengaruh signifikan terhadap popularitas merek.

$\mathrm{H}_{2}=$ video berpengaruh signifikan terhadap popularitas merek.

$\mathrm{H}_{3}=$ caption berpengaruh signifikan terhadap popularitas merek.

$\mathrm{H}_{4}=$ pesan visual lebih efektif daripada pesan verbal

Berdasarkan waktu post, Brookes (2010), melaporkan bahwa posting di hari Jumat 64\% lebih efektif daripada hari Minggu dan 13\% lebih efektif daripada hari Sabtu. Sedangkan post di hari Jumat hanya 7\% lebih efektif daripada Senin dan 3\% lebih efektif daripada Selasa dan Rabu. Artinya posting pada weekday (Senin-Jum'at) lebih efektif daripada posting pada weekend (Sabtu-Minggu). Berdasarkan jam, posting sebelum tengah hari (00:00-12:00) 65\% lebih efektif daripada sore hari (12:01-23:59 malam). Hal ini memperkuat teori bahwa umumnya konsumen mengecek pesan di sosial media pada pagi hari sebelum memulai aktivitasnya. Buddy Media (2012) dan (Sabate, dkk., 2014), melaporkan bahwa posting pada jam sibuk (08:00-18:00) 30\% lebih efektif daripada non-jam sibuk (18:01-07:59) dan posting pada weekday dinilai lebih efektif daripada weekend (Sabate, dkk., 2014). Namun Schultz (2017) dalam penelitiannya tidak menemukan adanya pengaruh signifikan dari weekday terhadap popularitas merek. Adapun efektivitas ini diukur dari keterlibatan fans terhadap suatu post dalam bentuk memberikan like, share, views (video), dan komentar. Maka hipotesis penelitian dirumuskan sebagai berikut:

$\mathrm{H}_{5}=$ jam posting berpengaruh signifikan terhadap popularitas merek.

$\mathrm{H}_{6}=$ hari posting berpengaruh signifikan terhadap popularitas merek.

$\mathrm{H}_{7}=$ posting pada jam sibuk lebih efektif daripada posting pada non-jam sibuk.

$\mathrm{H}_{8}=$ posting pada weekday lebih efektif daripada posting pada weekend. 
Komunikasi di sosial media dalam bentuk fitur komentar memungkinkan merek untuk berinteraksi aktif secara lamgsung dengan konsumen. Dalam komunikasi pemasaran dikenal adanya dua bentuk komunikasi, yakni pemasaran inbound dan outbond. Kallio (2015), menjelaskan bahwa pemasaran outbound mengacu kepada bentuk komunikasi satu arah (one-way communication) dimana perusahaan melakukan promosi atau branding tanpa ada interaksi langsung dengan konsumen. Tools yang sering digunakan antara lain televisi, majalah, radio, pameran, atau direct mail letter. Adapun pemasaran inbound merujuk kepada bentuk komunikasi dua arah (two-way communication) dimana pemasar atau merek dapat berkomunikasi langsung secara aktif dengan konsumen. Dengan adanya fitur komentar, sosial media menjadi alat yang sangat efektif untuk membangun komunikasi dua arah dengan konsumen.

Komunikasi merek mempengaruhi cara konsumen berfikir dan merasakan suatu merek (Hudson dkk., 2015). Interaktivitas post dalam bentuk dialog tanya jawab, promosi dan kontes, link ke website lain, vote, atau tipe lain yang memungkinkan konsumen berinteraksi secara aktif diketahui dapat meningkatkan keterlibatan konsumen terhadap merek di sosial media (S. S. Wang, Lin, \& Liang, 2018). Vukasović \& Strašek (2014), menjelaskan bahwa agar sebuah merek survive, perlu dibangun interaksi secara aktif sehingga menjadikan fans mudah untuk mengakses merek, strategi komunikasi perlu dilakukan secara menarik melalui nama merek dan layanannya untuk mengembangkan kedekatan merek dengan konsumen. Dalam penelitian ini, kami membagi ke dalam dua jenis interaksi yakni interaksi aktif dimana admin merek aktif membalas komentar fans, dan interkasi pasif dimana admin merek tidak pernah membalas komentar fans. Pada umumnya konsumen suka berinteraksi aktif dengan merek, bertukar pikiran, menyampaikan saran untuk pengembangan produk dan layanan, bertanya, atau bahkan mengkritisi merek tersebut. Hal ini mejadikan kajian mengenai interaksi brand menjadi isu krusial dalam pengembangan popularitas merek di sosial media. Maka, hipotesis yang selanjutnya kami kembangkan adalah sebagai berikut:

$\mathrm{H}_{9}=$ interaksi merek berpengaruh signifikan terhadap popularitas merek.

$\mathrm{H}_{10}=$ interkasi merek aktif lebih efektif daripada interaksi merek pasif.

Penelitian terdahulu dengan demikian telah menujukkan hasil pengaruh konten dan waktu post terhadap popularitas merek di sosial media. Indikator popularitas yang digunakan pun cukup beragam, seperti jumlah likes, komentar (Sabate dkk., 2014) dan share (Schultz, 2017; Su, Reynolds, \& Sun, 2018; Kaur, Balakrishnan, Rana, \& Sinniah, 2019). Variabel dependent yang diteliti juga sangat beragam seperti konten video, gambar, jumlah karakter teks (Sabate, dkk., 2014), link, caption, vividnes (Su dkk., 2018; Schultz, 2017), tipe/jenis konten (Schultz, 2017), dan timing post (Buddy Media, 2012; Sabate dkk., 2014; Schultz, 2017). Kami masih melihat adanya dua gap dari penelitian terdahulu. Pertama, belum ada yang menjelaskan tentang pengaruh interaksi merek terhadap popularitas brand. Kedua, belum ada yang menjelaskan indikator views sebagai indikator popularitas merek. Padahal menurut pengamatan kami, video menjadi konten yang cukup dominan dipost oleh top brand pada penelitian ini. Sedangkan keterlibatan yang lebih banyak dilakukan user pada konten video adalah views daripada likes, komentar, ataupun sharing. Memberikan hasil analisa atas gap tersebut menjadi kebaruan dari penelitian ini. 
Penelitian ini memiliki dua tujuan, yakni 1) mengetahui pengaruh konten (video, gambar, caption), waktu post (hari, jam), dan interaksi merek terhadap popularitas merek di sosial media. Kedua, 2) mengetahui konten, waktu post, dan bentuk interaksi merek yang paling efektif untuk meningkatkan popularitas merek di sosial media. Penelitian ini memberikan kontribusi praktis kepada pemasar dan kontribusi teoritis analytis kepada akademisi dan peneliti tentang strategi pengelolaan sosial media yang efektif untuk branding di sosial media.

\section{METODE}

Metode penelitian ini adalah kuantitatif untuk mengkaji hubungan antar variabel yang dianalisis berdasarkan prosedur statistik (Creswell, 2013). Pengumpulan data primer dilakukan melalui pengamatan terhadap aktivitas enam (6) top merek internasional kategori produk makanan-minuman di fan page Facebook selama 1 bulan, yakni pada 13 Maret 13 April 2018. Kriteria top merek merujuk pada fanpagelist.com pada bulan Maret-April 2018, yakni Red Bull, Coca Cola, Monster Energy, Starbucks Coffee, Nuttela, dan Nescafe. Adapun follower fan page merek tersebut berasal dari berbagai negara. Urutan top brand di fanpagelist.com setiap saat dapat berubah sehingga waktu penentuan ranking top brand perlu ditentukan.

Analisis statistik digunakan untuk menguji pengaruh variabel independen terhadap popularitas merek. Model regresi logit dipilih sebab variabel independen (X) dan variabel dependen (Y) berupa dummy kategorik bertingkat. Evaluasi regresi logistik meliputi uji goodness of fit, uji overall model fit, dan uji pengaruh variabel independent secara individu (Widarjono, 2010). Uji asumsi dalam model logistik adalah non-multikolinearitas dimana suatu model dikatakan non-multikolinearitas jika nilai toleransi kolinearitas $>0,1$ atau nilai VIF $<10$ atau jika standar error koefisien beta $<1$ (Setyobudi, 2016).

Uji Goodness of fit bertujuan untuk mengetahui kebaikan model dengan menggunakan ukuran koefisien determinasi. Garis regresi yang diukur adalah ukuran yang kurang baik atau ukuran palsu sehingga disebut Pseudo $R^{2}$. Jenis Pseudo $R^{2}$ yang digunakan adalah Pseudo $R^{2}$ Nagelkerke karena memiliki kelebihan sebagai hasil modifikasi dari Pseudo $R^{2}$ Cox and Snell yang dinilai masih memiliki kekurangan (Widarjono, 2010). Kriteria uji yang digunakan yakni semakin besar nilai Pseudo $R^{2}$ maka semakin baik garis regresi logistiknya (Widarjono, 2010), nilai Pseudo $R^{2}$ yang dianggap baik adalah lebih dari $70 \%$ (Setyobudi, 2016).

Uji overall model fit digunakan untuk menguji pengaruh variabel $\mathrm{X}$ secara simultan terhadap variabel Y. Uji ini mengikuti distribusi chi square dengan derajat kebebasan (degree of freedom) $\mathrm{n}-\mathrm{k}$, dimana $\mathrm{n}$ adalah jumlah observasi sedangkan $\mathrm{k}$ adalah jumlah parameter estimasi dalam model kecuali konstanta. Kriteria uji, $\mathrm{H}_{0}$ ditolak jika chi square $\left(X^{2}\right)$ hitung > chi square $\left(X^{2}\right)$ tabel, yang artinya semua variabel $X$ secara simultan berpengaruh terhadap popularitas merek. Adapun uji Wald digunakan untuk uji signifikansi variabel independen secara individu. Uji Wald mengikuti distribusi chi square $\left(X^{2}\right)$, sehingga kriteria uji yang digunakan adalah $\mathrm{H}_{0}$ ditolak jika probabilitas chi square $\left(X^{2}\right)$ hitung $<$ taraf signifikansi $\alpha$ (Widarjono, 2010). Selanjutnya dilakukan uji perbedaan dengan menggunakan Mann Whitney untuk perbedaan dua kategorik dan Kruskal Wallis untuk perbedaan lebih dari dua kategorik. 
Kedua uji perbedaan ini dilakukan untuk menentukan konten, waktu post, dan interaksi merek yang paling efektif untuk meningkatkan popularitas merek.

Tabel 1. Definisi dan pengukuran variabel

\begin{tabular}{|c|c|c|}
\hline Variabel & Definisi & Keterangan dan Dummy \\
\hline Y. Likes & Jumlah like pada sebuah post & $\begin{array}{l}\text { Jumlah likes } \\
\text { 0: "tidak ada like" } \\
\text { 1: "ada satu atau lebih like" }\end{array}$ \\
\hline Y. Komentar & $\begin{array}{l}\text { Jumlah komentar fans pada } \\
\text { sebuah post }\end{array}$ & $\begin{array}{l}\text { Jumlah komentar } \\
\text { 0: "tidak ada komentar" } \\
\text { 1: "ada satu atau lebih komentar" }\end{array}$ \\
\hline Y. Share & Jumlah share pada sebuah post & $\begin{array}{l}\text { Jumlah share } \\
\text { 0: "tidak ada share" } \\
\text { 1: "ada satu atau lebih share" }\end{array}$ \\
\hline Y. View & $\begin{array}{l}\text { Jumlah fans yang melihat tayangan } \\
\text { pada sebuah post video }\end{array}$ & $\begin{array}{l}\text { Jumlah view } \\
\text { 0: "tidak ada view" } \\
\text { 1: "ada satu atau lebih view" }\end{array}$ \\
\hline $\mathrm{X}_{1}$. Post Gambar & $\begin{array}{l}\text { Jumlah gambar yang dipost pada } \\
\text { satu hari }\end{array}$ & $\begin{array}{l}\text { Jumlah gambar } \\
\text { 0: "tidak ada post gambar" } \\
\text { 1: "ada satu atau lebih post gambar" }\end{array}$ \\
\hline$X_{2}$. Post Video & $\begin{array}{l}\text { Jumlah video yang dipost pada } \\
\text { satu hari }\end{array}$ & $\begin{array}{l}\text { Jumlah video } \\
\text { 0: "tidak ada post video" } \\
\text { 1: "ada satu atau lebih post video" }\end{array}$ \\
\hline $\mathrm{X}_{3}$. Caption & $\begin{array}{l}\text { Pesan teks pada post video/ } \\
\text { gambar, termasuk link/url }\end{array}$ & $\begin{array}{l}\text { Jumlah pesan teks } \\
\text { 0: "tidak ada caption" } \\
\text { 1: "ada caption" }\end{array}$ \\
\hline $\mathrm{X}_{4}$. Jam post & $\begin{array}{l}\text { Jam dari sebuah post } \\
\text { dipublikasikan }\end{array}$ & $\begin{array}{l}\text { 0: "tidak ada post" } \\
\text { 1: "non-jam sibuk" (00-7:59 dan 18.00-23:59 pada } \\
\text { hari Senin-Jumat; 00-7:59 dan 08:00-23:59 pada } \\
\text { hari Sabtu-Minggu) } \\
\text { 2: "jam sibuk" (08:00-12:00 dan 12:01-18:00 pada } \\
\text { Senin-Kamis, dan 08:00-15:00 pada Jumat) }\end{array}$ \\
\hline$X_{5}$. Hari post & Hari dari setiap post dipublikasikan & $\begin{array}{l}\text { 0: "tidak ada post" } \\
\text { 1: "hanya post di akhir pekan" (Jum'at jam } \\
\text { 15:00 sampai Minggu jam 24:00) } \\
\text { 2: "post di hari aktif" (Senin sampai Kamis) }\end{array}$ \\
\hline $\mathrm{X}_{6}$. Komentar admin & $\begin{array}{l}\text { Komentar admin terhadap } \\
\text { komentar fans pada setiap post }\end{array}$ & $\begin{array}{l}\text { 0: "tidak ada komentar" } \\
\text { 1: "ada satu atau lebih komentar" }\end{array}$ \\
\hline
\end{tabular}

Sumber: Penulis (2017) dimodifikasi dari Sabate, dkk., (2014)

Pengukuran variabel dengan menggunakan dummy kategorik seperti disajikan pada Tabel 1. Adapun persamaan model ordinal regresi dengan Y dua kategori merujuk kepada Paputungan, Langi, \& Prang (2016), dituliskan sebagai berikut:

$$
\begin{aligned}
& \text { Logit } Y_{0}=\emptyset_{0}+\beta_{1} X_{1}+\beta_{2} X_{2}+\beta_{3} X_{3}+\beta_{4} X_{4}+\beta_{5} X_{5}+\beta_{6} X_{6} \\
& \text { Logit } Y_{1}=\emptyset_{1}+\beta_{1} X_{1}+\beta_{2} X_{2}+\beta_{3} X_{3}+\beta_{4} X_{4}+\beta_{5} X_{5}+\beta_{6} X_{6}
\end{aligned}
$$

Dimana $Y_{0}$ dan $Y_{1}$ adalah variable dependent popularitas merek untuk kategorik nol (0) dan satu (1). Mengacu kepada jumlah likes, shares, comments, dan views sebagaimana dijelaskan pada Tabel 1. Untuk $\emptyset_{0}$ dan $\emptyset_{1}$ adalah konstanta untuk kategori $\mathrm{Y}_{0}$ dan $\mathrm{Y}_{1} ; \beta_{1-6}$ adalah vektor koefisien untuk variabel independent $\mathrm{X}_{1}$ sampai $\mathrm{X}_{6} ; \mathrm{X}_{1}=$ gambar, $\mathrm{X}_{2}=$ video, $\mathrm{X}_{3}=$ caption, $\mathrm{X}_{4}=$ jam, $\mathrm{X}_{5}=$ hari, $\mathrm{X}_{6}=$ komentar admin. 


\section{HASIL DAN PEMBAHASAN}

Hasil penelitian diperoleh 443 data observasi, sehingga nilai $r$ tabel pada taraf signifikansi 0,05 adalah 0,082. Dengan membandingkan $r$ hitung (corrected item total correction) dan $r$ tabel, dapat diketahui bahwa semua item observasi adalah valid, kecuali gambar tidak valid dengan $r$ hitung $(-154)<0,082$ (Tabel 2) sehingga dihilangkan dalam analisis selanjutnya. Konten post pada penelitian ini lebih banyak menampilkan video dan caption sehingga gambar dinilai tidak valid untuk dijadikan instrumen penelitian. Hal ini juga dapat mungkin menunjukkan bahwa konten video dinilai lebih disukai dibandingkan gambar. Semua item observasi reliable dengan nilai Cronbach's alpha total $(0,870)>$ nilai pembanding $(0,60)$.

Tabel 2. Hasil uji validitas dan reliabilitas

\begin{tabular}{ccc}
\hline Item Observasi & Corrected Item-Total Correlation & Cronbach's Alpha if Item Deleted \\
\hline Gambar & $-0,154^{\sharp}$ & 0,892 \\
Video & $0,741^{\wedge}$ & 0,847 \\
Caption & $0,759^{\wedge}$ & 0,845 \\
Jam & $0,694^{\wedge}$ & 0,850 \\
Hari & $0,789^{\wedge}$ & 0,842 \\
Komentar Admin & $0,363^{\wedge}$ & 0,870 \\
Likes & $0,828^{\wedge}$ & 0,844 \\
Komentar Fans & $0,747^{\wedge}$ & 0,848 \\
Shares & $0,684^{\wedge}$ & 0,850 \\
Views & $0,747^{\wedge}$ & 0,847 \\
\hline
\end{tabular}

[^valid, $r$ hitung > 0,082; "tidak valid, $r$ hitung $<0,082$ ]

Sumber: Data Primer, 2018

Model logistik layak digunakan jika $X_{\text {hitung }}^{2}>X_{\text {tabel }}^{2}(\alpha$; df) atau jika nilai signifikansi deviance (sig.) > signifikansi $\alpha(0,05)$ (Widarjono, 2010). $X^{2}{ }_{\text {hitung }}$ (chi square deviance) berdasarkan Tabel 3 diketahui sebesar 41,019 dengan degree of freedom (df) 82, dengan demikian $X_{\text {hitung }}^{2}(41,019)>X_{\text {tabel }}^{2}(60,3915)$ dan nilai sig. deviance $(1,000)>0,05$ sehingga model logistik layak digunakan pada penelitian ini.

Tabel 3. Goodness of fit

\begin{tabular}{cccc}
\hline & Chi-Square & df & Sig. \\
\hline Pearson & 179,863 & 82 & 0,000 \\
Deviance & 41,026 & 82 & 1,000 \\
\hline \multicolumn{2}{l}{ Sumber: Data Primer, 2018}
\end{tabular}

Pseudo $R^{2}$ Nagelkerke menunjukkan sebesar 0,863 (Tabel 4), artinya model logistik memenuhi kriteria baik untuk digunakan, dimana variabel $\mathrm{X}$ dapat menjelaskan pengaruh sebesar $86,3 \%$ terhadap popularitas merek. 
Tabel 4. Nilai koefisien determinasi Pseudo $R^{2}$

\begin{tabular}{cc}
\hline Jenis Pseudo $\boldsymbol{R}^{2}$ & Nilai $\boldsymbol{P s e u d o}^{\boldsymbol{R}^{2}}$ \\
\hline Cox and Snell & 0,640 \\
Nagelkerke & 0,863 \\
McFadden & 0,755 \\
\hline
\end{tabular}

Sumber: Data Primer, 2018

Kami menemukan beberapa aspek penting yang perlu diperhatikan pemasar dalam branding di sosial media, yakni konten post, waktu post, dan interaksi merek dengan fans. Ketiga aspek tersebut terbukti berpengaruh sebesar 86,3\% terhadap popularitas merek Tabel 4.

Tabel 5, menunjukkan asumsi non-multikolinearitas terpenuhi yang ditunjukkan dengan nilai VIF setiap variabel $<10$, nilai tolerance $>0,1$ dan standar error koefisien beta $<1$.

Tabel 5. Hasil uji multikolinearitas

\begin{tabular}{|c|c|c|c|c|c|c|c|}
\hline \multirow{2}{*}{ Variabel } & \multicolumn{2}{|c|}{$\begin{array}{l}\text { Unstandardized } \\
\text { Coefficients }\end{array}$} & \multirow{2}{*}{$\begin{array}{c}\begin{array}{c}\text { Standardized } \\
\text { Coefficients }\end{array} \\
\text { Beta }\end{array}$} & \multirow{2}{*}{$t$} & \multirow{2}{*}{ Sig. } & \multicolumn{2}{|c|}{ Collinearity Statistics } \\
\hline & B & Std. Error & & & & Tolerance & VIF \\
\hline (Constant) & $-0,006$ & 0,024 & & $-0,233$ & 0,816 & & \\
\hline X1_Jam Publikasi & $-0,061$ & 0,022 & $-0,095$ & $-2,750$ & 0,006 & 0,348 & 2,875 \\
\hline X2_Hari Publikasi & 0,027 & 0,022 & 0,045 & 1,275 & 0,203 & 0,326 & 3,065 \\
\hline X3_Post Video & 0,888 & 0,028 & 0,861 & 31,490 & 0,000 & 0,553 & 1,807 \\
\hline X5_Post Teks & 0,048 & 0,034 & 0,048 & 1,425 & 0,155 & 0,367 & 2,724 \\
\hline X6_Komentar Admin & 0,102 & 0,027 & 0,087 & 3,800 & 0,000 & 0,795 & 1,258 \\
\hline X7 Follower & 0,022 & 0,023 & 0,020 & 0,966 & 0,334 & 0,969 & 1,033 \\
\hline
\end{tabular}

Sumber: Data Primer, 2018

Secara simultan Tabel 6 menunjukkan bahwa konten post, waktu post, dan interaksi merek bepengaruh signifikan terhadap popularitas merek ( $\mathrm{p}$-value $<0,001 ; X^{2}{ }_{\text {hitung }}(451,534)$ $>X_{\text {tabel }}^{2}(1,6354)$.

Tabel 6. Hasil uji overall model fit

\begin{tabular}{ccccc}
\hline Model & -2 Log Likelihood & Chi-Square & Df & Sig. \\
\hline Intercept Only & 513,424 & & \\
Final & 61,890 & 451,534 & 6 & $0,000^{* * *}$ \\
\hline$N_{\text {valid }}=442\left[Y_{(0)}=166 ; Y_{(1)}=275 ; Y_{(2)}=1 ; \alpha X_{\text {tabel }}^{2}=0,05 ; * * *\right.$ sig pada $\left.\alpha<0,001\right]$ & \\
Sumber: Data Primer, 2018 & &
\end{tabular}

Penemuan ini mengarahkan pada beberapa teori signifikan, strategi, dan implikasi manajerial bagi bisnis. Mou \& Shin (2018), melaporkan bahwa popularitas merek di sosial media merefleksikan pengalaman dan tingkat kepercayaan konsumen terhadap merek yang mempengaruhi persepsi dan keputusan pembelian mereka. Yang perlu digarisbawahi dari penelitian ini adalah bahwa jumlah follower merupakan prediktor yang kuat dari popularitas 
merek di sosial media sehingga kami memilih merek dengan jumlah follower terbanyak sebagai sampel observasi. Rutter, Roper, \& Lettice (2016), menyebutkan bahwa jumlah follower merek di sosial media mewakili kekuatan atau reputasi suatu merek. Seorang konsumen dapat mengendorse merek dengan mengikuti atau menyukai atau membagikan postingan mereka.

Dalam perspektif bisnis yang kompetitif, branding menjadi bagian yang sangat penting dalam meningkatkan dan menjaga keberlanjutan keunggulan kompetitif perusahaan. Salah satu tugas penting perusahaan kemudian adalah menyediakan sarana untuk berdiskusi tentang produk dan layanan dengan konsumen ataupun calon konsumen potensial serta membentuk gambaran positif perusahaan (Jucaitytė \& Maščinskienė, 2014). Kehadiran sosial media yang sangat digemari oleh masyarakat dapat digunakan sebagai jembatan penghubung antara merek atau perusahaan dengan konsumen. Penelitian ini memberikan informasi tentang strategi pengelolaan untuk meningkatkan popularitas merek di sosial media.

Hasil uji Wald Tabel 7 menunjukkan bahwa video ( $\mathrm{p}$-value $<0,001 ; \beta=+7,144$ ) dan caption ( $\mathrm{p}$-value $<0,001 ; \beta=+1,168$ ) berpengaruh signifikan dan positif terhadap popularitas merek. Koefisien yang bernilai positif menunjukkan bahwa peningkatan jumlah post video dan caption dapat meningkatkan popularitas merek. Temuan ini mendukung hasil studi Sabate dkk. (2014), Schultz (2017) dan Su dkk. (2018). Sedangkan uji Mann Whitney menunjukkan adanya perbedaan pengaruh yang signifikan terhadap popularitas merek (p-value < 0,001) antara adanya post video dan tidak ada post, dimana dengan posting satu atau lebih video (mean $=258,83$ ) berpengaruh lebih besar terhadap popularitas dibandingkan tidak ada post video (mean $=79,69$ ). Demikian halnya dengan pengaruh caption terhadap popularitas merek menunjukkan adanya perbedaan pengaruh yang signifikan ( $\mathrm{p}$-value $<0,001$ ) antara post yang tidak disertai caption dengan post yang disertai caption. Hasilnya menunjukkan bahwa post konten yang disertai caption (mean $=247,74$ ) lebih berpengaruh untuk meningkatkan popularitas merek daripada post yang tidak disertai caption (mean $=109,93$ ). Nilai mean rank pada post video dan caption menunjukkan bahwa post video (mean $=256,83$ ) lebih besar pengaruhnya terhadap popularitas merek dibandingkan dengan caption (mean $=247,74$ ). Penemuan ini mendukung Brookes (2010) dan Sabate, dkk. (2014), bahwa gambar dan video lebih disukai oleh user dan lebih efektif untuk meningkatkan popularitas merek. Ini artinya konten visual lebih efektif untuk meningkatkan popularitas daripada konten verbal. Dengan demikian, maka hipotesis $\mathrm{H}_{2}, \mathrm{H}_{3}$, dan $\mathrm{H}_{4}$ diterima, sedangkan $\mathrm{H}_{1}$ ditolak sebab gambar berdasarkan uji validitas tidak valid dalam model ini.

Branding di sosial media dengan demikian sangat dipengaruhi oleh kreativitas konten. Sharing konten yang menarik sangat potensial untuk meningkatkan jumlah follower. Sharma dkk. (2012) dan Hellberg (2015), melaporkan bahwa konten visual di sosial media berpengaruh signifikan terhadap keputusan pembelian konsumen. Sedangkan Rambe \& Jafeta (2017), melaporkan bahwa selain dipengaruhi oleh harga, preferensi merek khususnya pada konsumen muda dipengaruhi oleh adanya komunitas atau fan page merek online yang memungkinkan mereka terlibat langsung dengan merek. Konten yang menarik dalam hal ini memberikan pengaruh signifikan terhadap preferensi mereka. 
Tabel 7. Hasil uji Wald pengaruh video dan teks terhadap popularitas merek

\begin{tabular}{|c|c|c|c|c|c|c|c|}
\hline \multicolumn{5}{|c|}{ Wald test } & \multicolumn{3}{|c|}{ Mann Whitney Test } \\
\hline Variabel & Estimate & Std. Erro & Wald & Sig. & $\begin{array}{l}\text { Dummy } \\
\text { Variable }\end{array}$ & Mean Rank & $\begin{array}{l}\text { Asymp. Sig. } \\
\text { (2-tailed) }\end{array}$ \\
\hline$[\mathrm{Y}=0]$ & 5,137 & 0,919 & 31,226 & 0,000 & & & \\
\hline$[\mathrm{Y}=1]$ & 15,380 & 1,833 & 70,439 & 0,000 & & & \\
\hline Video & 7,144 & 0,888 & 64,652 & $0,000 * * *$ & $\begin{array}{l}0 \\
1\end{array}$ & $\begin{array}{c}79,69 \\
258,83\end{array}$ & $0,000 * * *$ \\
\hline Caption & 1,168 & 0,689 & 2,873 & $0,090^{*}$ & $\begin{array}{l}0 \\
1\end{array}$ & $\begin{array}{l}109,93 \\
247,74\end{array}$ & $0,000^{\star \star \star *}$ \\
\hline
\end{tabular}

[***signifikan pada $\alpha<0,001$; *signifikan pada $\alpha<0,1]$ Sumber: Data Primer, 2018

Konten visual ditemukan berpengaruh lebih besar daripada konten verbal. Hal ini mendukung studi Sharma dkk. (2012) bahwa kemampuan otak manusia dalam mengolah informasi visual lebih besar daripada informasi verbal karena sifat verbal yang dibatasi oleh kemampuan bahasa. Ini yang menyebabkan pesan video lebih disukai. Secara alamiah, manusia juga lebih menyukai informasi yang mampu membangkitkan respon emosional mereka. Reaksi emosi yang ditimbulkan oleh suatu konten dapat berupa emosi positif seperti perasaan romantis, energik, bahagia, rileks, kekanak-kanakan, atau bahkan emosi negatif seperti marah atau kesal (Long, 2014). Demikian halnya dalam konteks sosial media, Hellberg (2015) menyebutkan bahwa dengan melihat konten yang mampu membangkitkan respon emosional, konsumen akan tertarik untuk mencari lebih dalam tentang merek.

Konten post yang menarik dan high quality lebih banyak menerima keterlibatan konsumen (Geurin \& Burch, 2017). Redbull, salah satu merek yang kami observasi dalam penelitian ini merupakan merek minuman energi yang sering menempati posisi \#1 atau \#2 top merek untuk kategori food-beverage di Facebook dan Twitter. Popularitasnya yang tinggi didukung oleh kemampuannya dalam menampilkan video yang atraktif pada setiap postingan. Emosi umumnya menjadi alasan utama konsumen memilih sebuah merek. Redbull merupakan merek yang berhasil menjalin ikatan emosi dengan konsumennya melalui konten video-video olahraga ekstrim yang dibagikan melalui sosial media. Minuman energi sering dikaitkan dengan pesta, musik, (red-olahraga), yang sering dimaknai sebagai gaya hidup anak muda (Rambe \& Jafeta, 2017). Sebagai minuman energi, ia mengunakan emosi tersebut dan menuangkannya dalam konten olahraga yang menantang bagi target pasarnya.

Ada pesan bernilai positif yang disampaikan Redbull dalam setiap kontennya. Selain menampilkan logo, dalam setiap video Redbull hampir tidak pernah mengajak orang untuk minum Redbull. Konten marketingnya fokus untuk membangun ikatan emosi. Anthony Hearne, seorang Regional Director SEA, India, \& New Market Outbrain seperti dilansir dari laman Techniasia menyebutkan bahwa 82\% konsumen lebih menyukai konten merek yang memberikan nilai untuk mereka daripada konten yang hanya berisi iklan. Ia juga menyebutkan bahwa konten merupakan satu-satunya cara untuk memenangkan konsumen dalam perang 
merek di era digital ini (Iriansyah, 2016). Selaras dengan Kotler \& Keller (2009), bahwa manajemen merek bertujuan untuk menciptakan, mengkomunikasikan, dan mentransfer nilai kepada target pasar untuk menghasilkan profit.

Starbucks Coffee, juga menggunakan kekuatan konten untuk membangun hubungan emosi dengan konsumen. Starbucks memilih empat sosial media yang paling populer untuk branding, yakni Facebook untuk posting konten sosial (post berupa gambar, video, dan link), Instagram untuk mengembangkan merek image sebagai sebuah ikon pop (post berupa foto dengan gaya fashion), twitter untuk berinteraksi langsung dengan konsumen (menjawab pertanyaan dan retweet dari konsumen) dan Youtube untuk iklan budaya dan gaya hidup yang unik dengan post berupa resep, dokumenter, dan iklan emosional (Tong, 2016). Di fan page-nya, merek ini lebih sering menampilkan pesan berupa gambar atau video yang berisi update produk baru, layanan, dan aktivitas konsumen. Berbeda dengan Redbull yang tidak pernah secara langsung menampilkan ajakan minum produk ini, Starbucks pada sebagian kontennya tetap menampilkan ajakan mengkonsumsi produk ini melalui update produkproduk baru.

Dengan demikian, dapat disimpulkan bahwa kemampuan membuat dan menjual konten yang kreatif menjadi strategi utama dalam membangun branding di sosial media. Sharing konten visual yang menarik terutama video sangat efektif untuk meningkatkan jumlah likes, share, komentar, views dan tentu follower. Top merek yang kami observasi pada penelitian ini membuktikan bahwa popularitas mereka di sosial media tidak hanya karena daya tarik produknya tetapi juga karena umumnya mereka berhasil menyajikan konten visual yang menarik sesuai target pasarnya.

Hasil Tabel 8 menunjukkan adanya pengaruh signifikan dan negatif dari variabel jam posting terhadap popularitas merek (p-value $<0,05 ; \beta=-1,276$ ).

Tabel 8. Hasil uji Wald pengaruh jam dan hari post terhadap popularitas merek

\begin{tabular}{|c|c|c|c|c|c|c|c|}
\hline \multirow{2}{*}{ Variabel } & \multirow{2}{*}{ Estimate } & \multirow{2}{*}{ Std. Error } & \multirow{2}{*}{ Wald } & \multirow{2}{*}{ df } & \multirow{2}{*}{ Sig. } & \multicolumn{2}{|c|}{ 95\% Confidence Interval } \\
\hline & & & & & & Lower Bound & Upper Bound \\
\hline$[\mathrm{Y}=0]$ & 5,137 & 0,919 & 31,226 & 1 & 0,000 & 3,335 & 6,939 \\
\hline$[\mathrm{Y}=1]$ & 15,380 & 1,833 & 70,439 & 1 & 0,000 & 11,788 & 18,972 \\
\hline Jam & $-1,276$ & 0,477 & 7,145 & 1 & $0,008^{* *}$ & $-2,212$ & $-0,340$ \\
\hline Hari & 0,431 & 0,484 & 0,795 & 1 & $0,373^{\wedge}$ & $-0,517$ & 1,379 \\
\hline
\end{tabular}

[**signifikan pada $\alpha<0.05$; ^tidak signifikan]

Sumber: Data Primer, 2018

Artinya jam berpengaruh terhadap popularitas merek namun penambahan jumlah jam post dalam sehari dapat menurunkan keterlibatan user baik dalam bentuk like, share, komentar, maupun views. Hal ini dapat dipahami bahwa jika dalam satu hari merek memposting beberapa konten di jam yang berbeda, user hanya akan memilih post yang disukai untuk terlibat lebih dalam didalamnya. Temuan ini mendukung sebagian penelitian Sabate dkk. (2014) yang bahwa jam post berpengaruh signifikan terhadap jumlah komentar namun tidak berpengaruh terhadap jumlah likes. Namun, mereka menyebutkan 
pengaruhnya signifikan positif sedangkan temuan kami menunjukkan pengaruh signifikan negatif. Adapun hari post tidak ditemukan adanya pengaruh signifikan terhadap popularitas merek. Temuan ini juga mendukung hasil studi Sabate dkk. (2014) namun bertentangan dengan Brookes (2010).

Uji perbedaan Tabel 9, menunjukkan terdapat perbedaan signifikan antara post pada jam-sibuk dan non-jam sibuk (p-value $<0,001$ ), dimana posting konten pada jam sibuk ( mean $=269.71$ ) berpengaruh lebih besar terhadap popularitas merek dibandingkan posting pada non-jam sibuk (mean =233.74). Dengan demikian, implikasi manajerialnya adalah pemasar dapat mempertimbangkan untuk posting konten diantara hari Senin-Kamis pukul 08.00-18.00 dan hari Jumat pukul 08.00-15.00. Pada waktu tersebut terbukti lebih efektif untuk mendapatkan respon user yang lebih tinggi.

Meskipun hari publikasi tidak ditemukan adanya pengaruh signifikan, namun uji Kruskal Wallis menunjukkan bahwa terdapat perbedaan signifikan ( $p$-value $<0,001$ ) antara post pada weekday dan weekend, dimana post weekday (mean $=239,03$ ) lebih efektif daripada weekend (mean $=236,46$ ). Hasil ini mendukung laporan Brookes (2010), bahwa post konten di hari Senin-Jumat lebih efektif dibandingkan post di hari Sabtu dan Minggu. Dengan demikian, maka $\mathrm{H}_{5}, \mathrm{H}_{7}$, dan $\mathrm{H}_{8}$ diterima, sedangkan $\mathrm{H}_{6}$ ditolak.

Tingginya respon baik berupa likes, shares, views, maupun komentar tidak hanya dipengaruhi oleh konten tetapi juga dipengaruhi oleh waktu post. Diperlukan timing yang tepat untuk mendapatkan respon post yang maksimal. Hellberg (2015), melaporkan bahwa suasana hati dan timing berpengaruh terhadap perilaku konsumen dalam keterlibatannya terhadap konten di sosial media. Di saat mereka sibuk misalnya, konten hanya akan dilihat sekilas atau hanya memberikan like tanpa memberikan respon lebih dalam seperti membagikan dan berkomentar. Beberapa yang sangat tertarik terhadap konten tersebut mungkin akan menyimpannya untuk dilihat kembali di saat senggang.

Tabel 9. Uji Kruskal Wallis pada jam dan hari publikasi

\begin{tabular}{ccccc}
\hline Variabel & Dummy Variabel & N & Mean Rank & Asym Sig.(2-tailed) \\
\hline Jam & tidak ada post & 146 & 167,91 & $0,000^{\star * *}$ \\
& post pada non-jam sibuk & 184 & 233,74 & \\
& post pada jam sibuk & 111 & 269,71 & \\
Total & 441 & & \\
\hline \multirow{2}{*}{ Hari } & tidak ada post & 105 & 168,39 & $0,000^{* * *}$ \\
& post weekend & 129 & 236,46 & \\
& post weekday & 208 & 239,03 & \\
& Total & 442 & & \\
\hline
\end{tabular}

***signifikan berbeda pada $\alpha<0,001$

Interaksi merek dalam menjaga hubungannya dengan komunitas konsumen berperan penting dalam mengembangkan perilaku pembelian konsumen (Chen, Luo, \& Ching, 2008). Merek yang mampu menjaga hubungan interaktif dengan followernya terbukti 
memiliki rate engagement post yang tinggi dan popularitas yang lebih tinggi di sosial media. Artinya dengan interaksi aktif, jumlah keterlibatan user pada setiap post akan lebih tinggi.

Tabel 10. Hasil uji Wald

\begin{tabular}{|c|c|c|c|c|c|c|c|}
\hline \multirow{2}{*}{ Variabel } & \multirow{2}{*}{ Estimate } & \multirow{2}{*}{ Std. Error } & \multirow{2}{*}{ Wald } & \multirow{2}{*}{ df } & \multirow{2}{*}{ Sig. } & \multicolumn{2}{|c|}{ 95\% Confidence Interval } \\
\hline & & & & & & Lower Bound & Upper Bound \\
\hline$[\mathrm{Y}=0]$ & 5,137 & 0,919 & 31,226 & 1 & 0,000 & 3,335 & 6,939 \\
\hline$[\mathrm{Y}=1]$ & 15,380 & 1,833 & 70,439 & 1 & 0,000 & 11,788 & 18,972 \\
\hline Komentar Admin & 3,087 & 1,094 & 7,963 & 1 & $0,005^{\star *}$ & 0,943 & 5,230 \\
\hline
\end{tabular}

[**signifikan pada $\alpha<0,05]$ Sumber: Data Primer, 2018

Kami menemukan bahwa administrator yang aktif merespon komentar fans-nya berpengaruh signifikan dan positif terhadap popularitas merek ( $\mathrm{p}$-value $<0,05 ; \beta=+3,087$ ) (Tabel 10). Pengaruhnya signifikan berbeda saat admin merespon komentar dan saat tidak memberikan respon komentar (p-value $<0,001$ ), dimana adanya respon terhadap komentar fans (mean $=268,99$ ) memiliki efek lebih besar terhadap popularitas daripada tidak adanya balasan komentar (mean $=208,15$ ) (Tabel 11). Hal ini membuktikan bahwa konsumen lebih menyukai merek yang aktif membangun interaksi dua arah dibandingkan merek yang pasif atau hanya interaksi satu arah. Dengan demikian, maka $\mathrm{H}_{9}$ dan $\mathrm{H}_{10}$ diterima.

Tabel 11. Uji perbedaan Mann Whitney dan Kruskal Wallis

\begin{tabular}{ccccc}
\hline Variabel & Dummy Variabel & N & Mean Rank & Asym Sig.(2-tailed) \\
\hline Komentar Admin & tidak ada komentar admin & 345 & 208,15 & \\
& ada satu atau lebih komentar & 97 & 268,99 & $0,000^{* *}$ \\
& Total & 442 & & \\
& & & \\
\hline
\end{tabular}

[**signifikan berbeda pada $\alpha<0,01]$ Sumber: Data Primer, 2018

Berdasarkan hasil yang sudah dipaparkan, maka persamaan regresi dari pengaruh variabel penelitian terhadap popularitas merek dapat dituliskan dalam persamaan 3 dan 4 berikut:

$$
\begin{aligned}
& \text { Logit } Y_{0}=5,137+7,144 X_{2}+1,168 X_{3}-1,276 X_{4}+0,431 X_{5}+3,087 X_{6} \\
& \text { Logit } Y_{1}=15,380+7,144 X_{2}+1,168 X_{3}-1,276 X_{4}+0,431 X_{5}+3,087 X_{6}
\end{aligned}
$$

Berdasarkan persamaan 3 dan 4 dapat dilihat perbedaan nilai konstansta yang cukup besar antara $Y_{0}\left(\varnothing_{0}=+5,137\right)$ dan $Y_{1}\left(\varnothing_{1}=+15,380\right)$, artinya popularitas merek dengan tanpa adanya keterlibatan dari user dalam bentuk likes, shares, komentar, dan views pada konten post di sosial media hanya akan menghasilkan popularitas sebesar 5,137; sedangkan dengan adanya keterlibatan tinggi dari user melalui posting konten secara intensif intensif dapat meningkatkan popularitas sebesar 15,380. Popularitas tersebut meningkat secara signifikan dengan memposting konten visual yang menarik $(\beta=+7,144)$, menambahkan caption 
$(\beta=+1,168)$, dan administrator yang aktif membalas komentar fans $(\beta=+3,087)$. Jam posting juga berpengaruh signifikan namun semakin banyak jumlah jam posting dalam sehari akan menurunkan jumlah keterlibatan user dalam setiap post $(\beta=-1,276)$. Hari post $(\beta=+0,431)$ meskipun tidak ditemukan adanya pengaruh signifikan, namun variabel dalam persamaan bernilai positif artinya penambahan hari post dalam satu pekan dapat meningkatkan popularitas sebesar 0,431 .

Setiap perusahaan modern pada akhirnya akan berusaha untuk meningkatkan layanan komunikasi yang memungkinkan mereka untuk berinteraksi dengan konsumen atau calon konsumen potensial dari produk atau layanannya secara efektif. Komunitas merek di sosial media dalam hal ini menjadi jembatan antara merek dan konsumen untuk berinteraksi langsung mengenai produk atau layanan atau bahkan menguji loyalitas untuk selanjutnya menjadi dasar bagi perusahaan untuk mengembangkan produk atau layannya. Melalui hadirnya sosial media, perusahaan memiliki peluang untuk memonitor konsumen secara mendalam, meningkatkan kinerja produk dan layanan untuk meningkatkan kesadaran merek, menciptakan hubungan yang kuat dengan konsumen, dan tentu saja meningkatkan penjualan. Untuk mewujudkan hal tersebut, diperlukan interaksi dua arah antara merek dengan konsumen dimana sosial media menjadi sarana yang efektif karena jangkauannya sangat luas, kecepatan sampainya pesan sangat tinggi, dan dapat diakses kapan pun dan dimanapun.

\section{SIMPULAN}

Jam post, konten video, caption, dan komentar admin berpengaruh signifikan terhadap popularitas merek, sedangkan hari post tidak ditemukan adanya pengaruh. Meskipun hari post tidak ditemukan adanya pengaruh signifikan, uji perbedaan menunjukkan bahwa post pada weekday lebih efektif daripada weekend. Dengan demikian, waktu post yang paling efektif untuk meningkatkan popularitas merek di sosial media adalah Senin-Kamis pukul 08.00-18.00 dan Jumat pukul 08.00-15.00; konten post yang paling efektif adalah video, serta admin yang aktif membangun interaksi dua arah dengan fans lebih efektif untuk meningkatkan popularitas merek.

Implikasi manajerialnya adalah pertama, penting bagi perusahaan untuk menyajikan konten visual yang menarik untuk meningkatkan keterlibatan user. Kedua, waktu post diatur sedemikian serupa sehingga mampu menarik banyak keterlibatan user, sebagaimana waktu efektif yang direkomendasikan berdasarkan temuan penelitian ini. Ketiga, administrator merek perlu dipilih orang yang memiliki kemampuan komunikasi antarpersonal yang baik, ramah, dan bersedia membantu kesulitan konsumen berkenaan dengan produk atau layanan merek. Adapun kelemahan penelitian ini adalah pengumpulan data hanya dikumpulkan secara kuantitatif sehingga tidak ada analisa mendalam tentang jenis tipe pesan video yang paling efektif untuk meningkatkan popularitas, padahal konten memberikan kontribusi yang paling besar terhadap popularitas, sehingga tipe pesan pada konten video yang paling efektif untuk meningkatkan popularitas perlu diteliti lebih lanjut. 


\section{PUSTAKA ACUAN}

Abidin, S. Z., Effendi, R. A. A. R. A., Ibrahim, R., \& Idris, M. Z. (2014). A semantic approach in perception for packaging in the SME's food industries in Malaysia: a case study of Malaysia food product branding in United Kingdom. Procedia - Social and Behavioral Sciences, 115, 115-130. https://doi.org/10.1016/j.sbspro.2014.02.420

Brookes, E. J. (2010). The Anatomy of a Facebook Post Study on Post Performance by Type, Day of Week, and Time of Day. Retrieved from https://marketingavatar.files.wordpress. com/2010/11/the-anatomy-of-a-facebook-post.pdf

Buddy Media. (2012). Strategies for Effective Tweeting: A Statistical Review Introduction 3. Retrieved from www.buddymedia.com

Chen, J., Luo, M. M., \& Ching, R. K. H. (2008). Virtual Experiential Marketing on Online Customer Intentions and Loyalty. In Proceedings of the 14thst Hawaii International Conference on System Sciences, 1-10. Hawaii: IEEE.

Combe, C. (2006). Introduction to e-Business: Management and Strategy. Oxford: ButterworthHeinemann. Retrieved from https://zodml.org/sites/default/files/Introduction_to_eBusiness_Management_and_Strategy.pdf

Creswell, J. W. (2013). Research Design Pendekatan Kualitatif, Kuantitatif, dan Mixed (Ketiga). Yogyakarta: Pustaka Pelajar.

Gamboa, A. M., \& Gonçalves, H. M. (2014). Customer loyalty through social networks: Lessons from Zara on Facebook. Business Horizons, 57(6), 709-717. https://doi.org/10.1016/J. BUSHOR.2014.07.003

Geurin, A. N., \& Burch, L. M. (2017). User-generated branding via social media: An examination of six running brands. Sport Management Review, 20, 273-284. https:// doi.org/10.1016/j.smr.2016.09.001

Hanifawati, T., Suryantini, A., \& Mulyo, J. H. (2017). Pengaruh Atribut Kemasan Makanan dan Karakteristik Konsumen Terhadap Pembelian. Agriekonomika, 6(9), 73-86. https://doi. org/http://dx.doi.org/10.21107/agriekonomika.v6i1.1895

Hellberg, M. (2015). Visual Brand Communication on Instagram: A study on consumer engagement. Hanken School of Economics. Retrieved from https://helda.helsinki.fi/ bitstream/handle/10138/156026/hellberg.pdf?sequence $=4$

Hudson, S., Huang, L., Roth, M. S., \& Madden, T. J. (2015). The influence of social media interactions on consumer brand relationships: A three-country study of brand perceptions and marketing behaviors. International Journal of Research in Marketing. https://doi.org/10.1016/j.jiresmar.2015.06.004

Iriansyah, F. Y. (2016). Anthony Hearne: Content Marketing, dari Hati Turun ke Kepala. Retrieved October 31, 2018, from https://id.techinasia.com/outbrain-content-marketing

Jothi, P. S., Neelamalar, M., \& Prasad, R. S. (2011). Analysis of social networking sites: A study on effective communication strategy in developing brand communication. Journal of Media and Communication Studies, 3(7), 234-242. Retrieved from http://www. academicjournals.org/article/article1380266912_Jothi dkk.pdf

Jucaitytė, I., \& Maščinskienè, J. (2014). Peculiarities of Social Media Integration into Marketing 
Communication. Procedia - Social and Behavioral Sciences, 156, 490-495. https://doi. org/10.1016/J.SBSPRO.2014.11.227

Kallio, K. (2015). The Effectiveness of Social Media as a Marketing Communication Tactic, Case Gina Tricot Ltd. Vaasan Ammattikorkeakoulu University of Applied Sciences. Retrieved from https://www.theseus.fi/bitstream/handle/10024/98146/Kallio_Kira. pdf?sequence $=1$ \&isAllowed $=y$

Kaur, W., Balakrishnan, V., Rana, O., \& Sinniah, A. (2019). Liking, sharing, commenting and reacting on Facebook: User behaviors' impact on sentiment intensity. Telematics and Informatics, (December), 1-12. https://doi.org/10.1016/j.tele.2018.12.005

Kemp, S. (2016). Digital in 2016 - We Are Social. Retrieved February 10, 2017, from https:// wearesocial.com/special-reports/digital-in-2016

Kim, A. J., \& Johnson, K. K. P. (2016). Computers in Human Behavior Power of consumers using social media : Examining the influences of brand-related user-generated content on Facebook. Computers in Human Behavior, 58, 98-108. https://doi.org/10.1016/j. chb.2015.12.047

Kotler, P., \& Keller, K. L. (2009). Manajemen Pemasaran edisi 12 Jilid 1. Jakarta Barat: PT Indeks.

Kudeshia, C., \& Kumar, A. (2018). Social eWOM: does it affect the brand attitude and purchase intention of brands? Management Research Review, 40(3). https://doi.org/10.1108/ MRR-07-2015-0161

Lin, H. C., Swarna, H., \& Bruning, P. F. (2017). Taking a global view on brand post popularity: Six social media brand post practices for global markets. Business Horizons, 60(5), 621-633. https://doi.org/10.1016/j.bushor.2017.05.006

Long, K. E. (2014). "How does it make you feel?”; A visual content analysis of emotions portrayed consumer brands images on social media. Lund Universitet, Lund. Retrieved from http:// lup.lub.lu.se/luur/download?func=downloadFile\&recordOId=4770234\&fileOId=4770238

Magnini, V. P., Karande, K., Singal, M., \& Kim, D. (2013). The effect of brand popularity statements on consumers ' purchase intentions: The role of instrumental attitudes toward the act. International Journal of Hospitality Management, 34, 160-168. https:// doi.org/10.1016/j.ijhm.2013.02.010

Mou, J., \& Shin, D. (2018). Effects of social popularity and time scarcity on online consumer behaviour regarding smart healthcare products : An eye-tracking approach. Computers in Human Behavior, 78, 74-89. https://doi.org/10.1016/j.chb.2017.08.049

Paputungan, N. W., Langi, Y. A. R., \& Prang, J. D. (2016). Analisis Regresi Logistik Ordinal Pada Tingkat Kepuasaan Pengguna Jasa Terhadap Pelayanan di Bandara Internasional Sam Ratulangi Manado. JdC, 5(2), 72-79.

Rambe, P., \& Jafeta, R. J. (2017). Impact of social media advertising on high energy drink preferences and consumption. Journal of Applied Business Research, 33(4), 653-668. https://doi.org/10.19030/jabr.v33i4.9977

Rangkuti, F. (2009). Strategi Promosi yang Kreatif dan Analisis Kasus Integrated Marketing Communication. Jakarta: Gramedia Pustaka Utama. 
Rog, N. (2014). The Influence of Content Type of Facebook Messages on the Effectiveness of the Message "And the moderating role of consumer brand relationship." University of Twente. Retrieved from https://essay.utwente.nl/65053/1/Rog Nicky -s 1247549 scriptie.pdf

Rutter, R., Roper, S., \& Lettice, F. (2016). Social media interaction, the university brand and recruitment performance. Journal of Business Research Social, 69, 3096-3104. https:// doi.org/10.1016/j.jbusres.2016.01.025

Sabate, F., Berbegal-mirabent, J., Cañabate, A., \& Lebherz, P. R. (2014). Factors influencing popularity of branded content in Facebook fan pages. European Management Journal, 32(6), 1001-1011. https://doi.org/10.1016/j.emj.2014.05.001

Saboo, A. R., Kumar, V., \& Ramani, G. (2016). Evaluating the impact of social media activities on human brand sales. International Journal of Research in Marketing, 33(3), 524-541. https://doi.org/10.1016/j.ijresmar.2015.02.007

Schultz, C. D. (2017). Proposing to your fans : Which brand post characteristics drive consumer engagement activities on social media brand pages? Electronic Commerce Research and Applications, 26, 23-34. https://doi.org/10.1016/j.elerap.2017.09.005

Setyobudi, R. F. (2016). Analisis Model Regresi Logistik Ordinal Pengaruh Pelayanan di Fakultas Matematika dan Ilmu Pengetahuan Alam Terhadap Kepuasan Mahasiswa FMIPA UNNES. Retrieved from http://lib.unnes.ac.id/25055/1/4112313024.pdf

Sharma, A., Bhosle, A., \& Chaudhary, B. (2012). Consumer Perception and Attitude towards the Visual Elements in Social Campaign Advertisement. IOSR Journal of Business and Management (IOSRJBM), 3(1), 6-17. Retrieved from www.iosrjournals.org

Su, N., Reynolds, D., \& Sun, B. (2018). How to make your Facebook posts attractive A case study of a leading budget hotel brand fan page. International Journal of Contemporary Hospitality Management, 27(8), 32. https://doi.org/10.1108/IJCHM-06-2014-0302

Swani, K., \& Milne, G. R. (2017). Evaluating Facebook brand content popularity for service versus goods o ff erings it. Journal of Business Research, 79, 123-133. https://doi. org/10.1016/j.jbusres.2017.06.003

Tong, S. (2016). More Than Coffee: Starbucks' Social Media Presence Analysis. Retrieved October 31, 2018, from https://blogs.commons.georgetown.edu/st798/files/2016/10/ Starbucks-Shimeng-Tong.pdf

Verhoef, P. C., \& Lemon, K. N. (2013). Successful customer value management: Key lessons and emerging trends. European Management Journal, 31(1), 1-15. https://doi.org/10.1016/J. EMJ.2012.08.001

Vukasovič, T. (2013). Brand Developing Relationships Through Social Media. In Management, Knowledge and Learning International Conference (pp. 19-21). Croatia. Retrieved from https://pdfs.semanticscholar.org/014f/0793c15b817dcdbe321cf0c62a9b5f67e366.pdf

Vukasović, T., \& Strašek, R. (2014). A Study on Effective Communication Strategy in Developing Brand Communication: Analysis of Social Networking Site. A Study on Effective Communication Strategy in Developing Brand Communication, 1(September), 3-6. Retrieved from http://www.iaeng.org/publication/WCE2014/WCE2014_pp690693.pdf 
Wang, S. S., Lin, Y., \& Liang, T. (2018). Posts that attract millions of fans: The effect of brand-post congruence. Electronic Commerce Research and Applications, 28, 73-85. https://doi.org/10.1016/j.elerap.2017.12.010

Wang, Y., Hsiao, S., Yang, Z., \& Hajli, N. (2015). Industrial Marketing Management The impact of sellers' social in fl uence on the co-creation of innovation with customers and brand awareness in online communities. Industrial Marketing Management. https:// doi.org/10.1016/j.indmarman.2015.12.008

Widarjono, A. (2010). Analisis Statistika Multivariat Terapan. Yogyakarta: UPP STIM YKPN.

Zadeh, A. H., \& Sharda, R. (2014). Modeling brand post popularity dynamics in online social networks. Decision Support Systems, 65, 59-68. https://doi.org/10.1016/j.dss.2014.05.003 